is a step by step manual of seven curriculum modules designed for the classroom teacher. The modules on self esteem and assertiveness use open ended questions to generate discussion. The unit on 'coping with hazards' promotes taking children on a tour of their classroom and building to understand potentially dangerous areas, including a brief discussion of physical injury risks from electrical and poisonous sources, in addition to teaching children about using a telephone in case of an emergency. 'It's my body' uses pictures to teach about body parts and anatomical names, followed by a fifth module to discuss the idea that certain body parts are 'private areas'. The final two units relate to discussion of 'feelings' and 'touching' using pictures, worksheets, and discussion.

Classroom teachers, parents of children with disabilities, social workers, and clinicians involved in child protective services will find this book quite useful as they will have some concrete ways of approaching this difficult topic. Since the text is rooted in an educational perspective, it will be useful for working with individual children or classrooms. Population based policy matters are not discussed in depth. In addition, this text is not an exploration of prevention of other forms of injury such as those caused by motor vehicles, pedestrian collisions, or firearms for children with disabilities, as the title might at first imply. Thus, it will not be of widespread interest to most childhood injury prevention professionals. A book about general injury prevention for children with disabilities is badly needed and would be most useful to practitioners and policy makers.

RAVI RAO

fohns Hopkins University, Baltimore, USA

\section{CALENDAR AND NOTICES}

Forthcoming events

Working with a net

A national conference to foster relationship and collaborative efforts in injury prevention will be hosted by the Centre for Injury Prevention and Research-KFL\&A/Queen's Teaching Health Unit, Kingston, Ontario, Canada. It will take place 12-15 June 1996 in Kingston, Ontario. Further details: Valerie Stenzel, Injury Prevention Officer, CIPR, 221 Portsmouth Avenue, Kingston, ON K7M 1V5.

World Congress '96: The Human Right for Safety

The 7th World Congress and Exhibition, 'Preventex '96', will be held 17-19 June 1996 in Budapest. It is sponsored by the National Commission for the Prevention of Accidents.
ISPCAN 11th International Congress

This meeting of the International Society for the Prevention of Child Abuse and Neglect will take place in Dublin, Ireland, 18-21 August 1996. Further details: ISPCAN Eleventh International Congress, Clifton House, Fitzwilliam Street Lower, Dublin 2, Ireland.

1996 International IRCOBI Conference on The Biomechanics of Impact

This conference will be held in Dublin, Ireland, 11-13 September 1996. Further details: IRCOBI Secretariat, INRETS, 109, Ave Salvador Allende, 69500 Bron, France.

\section{AAAM 40th Annual Conference}

The 40th annual conference of the American Association for the Advancement of Automotive Medicine will be held 7-9 October 1996 in Vancouver, British Columbia, Canada. Further details: AAAM Headquarters, fax: +1 7083909962 .

\section{Australian Playground Safety Conference}

The NSW Playground Safety Network is organizing this conference, which will be held in Sydney, Australia, 28-29 October 1996. Further details: Anne Warn, Health Promotion Unit, Central Coast Area Health Service, PO Box 361, Gosford, NSW 2250.

Pre-Congress Workshop, International Congress of Pediatrics

There will be a Pre-Congress Workshop, Injuries: Intentional and Unintentional, at the Ninth Asian Congress of Pediatrics to be held in Hong Kong in March 1997. Further details: Michael Gracey, MD, PhD, Principal Medical Adviser, Aboriginal Health Division, Health Western Australia, PO Box 8172, Stirling Street, Perth, WA 6849, Australia.

Injury Epidemiology and Injury Control An intensive five week program into the management of safety promotion and injury control will be held in spring 1997 in the Netherlands, organized by the WHO Collaborating Centres on Safety Promotion and Injury Control in cooperation with the Netherlands Institute for Health Sciences and the Netherlands School of Public Health. Further details: NIHES, Erasmus University Medical School, Hoboken, Room Ee 2185, PO Box 1738, 3000 DR Rotterdam, The Netherlands.

The 4th World Conference on Injury Prevention and Control

Wim Rogmans, Chairman of the National Steering Committee has issued the formal invitation to the next world conference, to be held in Amsterdam in 1998. Start saving! Further details: Conference Secretariat Injury Prevention and Control, PO Box 1558, 6501 BN Nijmegen, The Netherlands.

\section{MORE WEB SITES}

InterNet Health Resources

http://www.arcade.uiowa.edu/hardin-www/ md.html

MedWeb:Public Health

http://www.cc.emory.edu/WHSCL/medweb. ph.html

The Global Health Network http://www.pitt.edu/HOME/GHNet/GHNet. html

The World-Wide Web Virtual Library: Epidemiology

http://www.epibiostat.ucsf.edu/epidem/epidem.html

Canadian Society for International Health http://hpbl.hwc.ca:8500/

The Children's Safety Network (CSN) National Injury and Violence Prevention Resource Center at Education Development Center (EDC)

http://www.edc.org/HHD/csn

Building Bridges Between Traffic Safety and Public Health

http://www.edc.org/HHD/csn/buildbridges

NHTSA home page

http://www.nhtsa.dot.gov/>

InjuryNet (Harborview IPRC) electronic mailing list (aka a 'listserv') is available by sending an e-mail message to listproc@u.washington.edu saying subscribe injurynet (firstname lastname).

\section{Computer program review}

Not a site (I don't know where else to put it) but another sign of the technologic times is the excellent computer program Kids $\mathcal{E}$ Guns. This computer presentation is from the Program Against Violent Events (PAVE), which originates in the Violent Injury Prevention Center at Children's Memorial Hospital in Chicago. The focus of the center is the prevention of firearm injuries and child abuse. Katherine Kaufer Christoffel is the principal investigator and the computer program was supported by NHTSA and MCHB through an Emergency Medical Services for Children grant.

Kids $\mathcal{E}$ Guns is easily installed on Windows or Win95 and includes excellent graphics, statistics, a speech (that can be modified) references to important articles, and information about other organizations. Do try it! am certain you will be impressed.

Contributors who may be deterred by the journal's present 'non-indexed' status are reminded that once approval is given, all published peer reviewed papers in back issues will be indexed retroactively. 